\title{
1 Deep Sequencing Reveals Compartmentalized HIV-1 in the Semen of Men with and without
}

\section{STI-associated Urethritis}

3 Olivia D. Council ${ }^{1,2}$, Shuntai Zhou ${ }^{1}$, Chase D. McCann ${ }^{3}$, Irving Hoffman ${ }^{4}$, Gerald Tegha ${ }^{5}$,

4 Deborah Kamwendo ${ }^{5}$, Mitch Matoga ${ }^{5}$, Sergei L. Kosakovsky Pond ${ }^{6}$, Myron S. Cohen ${ }^{7}$ and Ronald

5 Swanstrom ${ }^{1,8 \#}$

6 1. Lineberger Comprehensive Cancer Center, University of North Carolina at Chapel Hill, Chapel $7 \quad$ Hill, NC, USA

8 2. Department of Microbiology and Immunology, University of North Carolina at Chapel Hill, 9 Chapel Hill, NC, USA

10 3. Department of Immunology and Microbial Pathogenesis, Weill Cornell Medicine, New York, $11 \quad$ NY, USA

12 4. Department of Medicine, University of North Carolina at Chapel Hill, Chapel Hill, NC, USA

13 5. University of North Carolina Project Malawi, Lilongwe, Malawi

14 6. Department of Biology, Temple University, Philadelphia, PA, USA

15 7. Division of Infectious Diseases, University of North Carolina at Chapel Hill, Chapel Hill, NC, $16 \quad$ USA

17 8. Department of Biochemistry and Biophysics, University of North Carolina at Chapel Hill, 18 Chapel Hill, NC, USA

Running Title: STI-coinfection and HIV-1 compartmentalization

21 Abstract Word Count: 250

22 Text Word Count: 5394

\section{Corresponding author}

25 Ronald Swanstrom

26 Rm. 22-006 Lineberger Comprehensive Cancer Center

27 University of North Carolina at Chapel Hill

28 Chapel Hill, North Carolina 27599-7295

29 Telephone: 919-966-5710. E-mail: ron_swanstrom@med.unc.edu 


\section{Abstract}

Concurrent sexually transmitted infections (STI) can increase the probability of HIV-1 transmission primarily by increasing the viral load present in semen. In this study, we explored the relationship of HIV-1 in blood and seminal plasma in the presence and absence of urethritis and

35 after treatment of the concurrent STI. Primer ID deep sequencing of the V1/V3 region of the HIV-

361 env gene was done for paired blood and semen samples from ART-naïve men living in Malawi

37 with $(\mathrm{n}=19)$ and without $(\mathrm{n}=5)$ STI-associated urethritis; for a subset of samples full length env

38 genes were generated for sequence analysis and to test entry phenotype. Cytokine concentrations

39 in the blood and semen were also measured, and a reduction in the levels of pro-inflammatory

40 cytokines was observed following STI treatment. We observed no difference in the prevalence of

41 diverse compartmentalized semen-derived lineages in men with or without STI-associated

42 urethritis, and these viral populations were largely stable during STI treatment. Clonal

43 amplification of one or a few viral sequences accounted for nearly $50 \%$ of the viral population

44 indicating a recent bottleneck followed by limited viral replication. We documented a case of

45 superinfection where the new strain was restricted to the genital tract. We conclude that the male

46 genital tract is a site where virus can be brought in from the blood, where localized sustained

47 replication can occur, where a superinfecting strain can persist, and where specific genotypes can

48 be amplified perhaps initially by cellular proliferation but further by limited viral replication.

\section{Importance}

HIV-1 is a sexually transmitted infection that co-exists with other STIs. Here we examine

52 the impact of a concurrent STI resulting in urethritis on the HIV-1 population within the male

53 genital tract. We found that viral populations remain largely stable even with treatment of the STI. 
54 These results show that viral populations within the male genital tract are defined by factors

55 beyond transient inflammation associated with a concurrent STI.

\section{Introduction}

Nearly two million new HIV-1 infections occur worldwide every year, predominately

60 through sexual transmission (1). Therefore, understanding the genotypic and phenotypic properties

61 of HIV-1 present in the male genital tract is vital for treatment and prevention strategies. It has

62 been well-established that the probability of sexual transmission of HIV-1 increases with an

63 increasing viral load (2-5), and there are several factors that can influence the concentration of

64 viral RNA present in semen. For example, stage of disease (6), CD4+ T cell count (7), and the

65 presence of inflammatory conditions (such as concurrent sexually transmitted infections [STI])

66 have all been demonstrated to increase the semen viral load (reviewed in (8)).

For semen-mediated transmission events, the transmitted/founder virus is most proximal

68 to the male genital tract at the time of transmission. Thus, the origin of virus in the male genital

69 tract is relevant to a fuller understanding of HIV-1 transmission. Often the virus present in semen

70 is similar to virus found in the blood (an equilibrated population), but there is also evidence that

71 the male genital tract is able to support independent replication of HIV-1. This fact is inferred from

72 observations of genetically distinct, or compartmentalized, HIV-1 populations in semen, as

73 compared to the virus found in the blood and other anatomical compartments (9-15). In addition,

74 several studies $(16,17)$ have reported the presence of HIV-1 RNA in the semen of men on

75 suppressive antiretroviral therapy, with undetectable blood plasma viral loads, implying that the

76 male genital tract can influence viral replication independent of the periphery and harbor an 
77 independent viral reservoir. It is therefore important to elucidate the factors that promote the

78 establishment and maintenance of compartmentalized viral lineages in the male genital tract. In the current study, we examined the effects of STI-associated urethritis on the

80 establishment and maintenance of compartmentalized lineages in the male genital tract by

81 comparing viral sequences in the blood and in seminal plasma using deep sequencing technology

82 with Primer ID $(18,19)$. We explored the possibility that STI-associated inflammation could act

83 to recruit $\mathrm{CD} 4+\mathrm{T}$ cells into the genital tract, thereby promoting a mixing of viral populations in

84 the blood and semen with a concomitant reduction in apparent compartmentalization, or

85 conversely the influx of cells could enhance the replication of locally produced virus and increase

86 compartmentalization. We also examined the viral population dynamics between blood and semen

87 over time to determine whether antibiotic treatment of the concurrent STI would impact HIV-1

88 compartmentalization. We detected no difference between the proportions of men who had

89 compartmentalized, semen-derived lineages, grouped by the presence or absence of urethritis.

90 Furthermore, antibiotic treatment of the STI did not observably impact the population dynamics

91 between the blood and the semen, at least in the short term. We conclude that STI-associated

92 inflammation is not a driving factor behind the establishment or maintenance of

93 compartmentalized lineages in the semen and that independent viral replication can occur

94 independently of inflammatory conditions.

96 Methods

97

98 Ethics Statement and Source of Clinical Samples. Blood and semen samples were collected as

99 part of a study examining the effects of genital tract inflammation on HIV-1 semen viral load (20). 
100 The study was approved by the Institutional Review Board at the University of North Carolina at

101 Chapel Hill. A subset of STI samples (12/19) were previously examined via a heteroduplex

102 tracking assay (9), and 2/5 control samples were previously examined via single genome

103 amplification (SGA) (10).

105 Deep Sequencing with Primer ID. Deep sequencing with Primer ID was performed as previously 106 described (19). Briefly, viral RNA was extracted from seminal and blood plasma using the 107 QIAamp Viral RNA Extraction Kit (Qiagen). Based on viral loads, up to 5,000 RNA copies (range:

108 196-5,000, mean: 3,161) were used for cDNA synthesis. cDNA was synthesized using the env 109 V1/V3 Primer ID primer (HXB2 positions 6585-7208): 5'110 GTGACTGGAGTTCAGACGTGTGCTCTTCCGATCTNNNNNNNNNCAGTCCATTTTGCT

111 CTACTAATGTTACAATGTGC-3' and SuperScript III Reverse Transcriptase (Invitrogen). The

112 final cDNA reaction contained the following: $0.5 \mathrm{mM}$ dNTP mix (KAPA) $0.25 \mu \mathrm{M} \mathrm{V} 1$-V3 reverse

113 primer, $5 \mathrm{mM}$ DTT, $6 \mathrm{U}$ RNaseOUT, and $30 \mathrm{U}$ SuperScript III RT in a total volume of $60 \mu \mathrm{l}$.

114 Initially a mixture containing dNTPs, cDNA primer and RNA template was incubated at $65^{\circ} \mathrm{C}$ for

1155 minutes, followed by $4^{\circ} \mathrm{C}$ for 2 minutes. Then DTT, RNaseOUT and SuperScript III were added

116 and the reactions were incubated for one hour at $50^{\circ} \mathrm{C}$, followed by one hour at $55^{\circ} \mathrm{C}$. Samples

117 were then heated to $70^{\circ} \mathrm{C}$ for 15 minutes to inactivate the SuperScript III prior to addition of RNase

$118 \mathrm{H}\left(2\right.$ units) and a final incubation at $37^{\circ} \mathrm{C}$ for 20 minutes. cDNA was purified using Agencourt

119 RNAclean XP beads (Beckman Coulter) at a volume ratio of 0.6:1 beads: cDNA. The beads were

120 washed four times with $70 \%$ ethanol. Purified cDNA was eluted in $24 \mu$ molecular grade water

121 (Corning), and the purification was repeated with a bead:cDNA ratio of 0.6:1. The purified cDNA

122 was again eluted in $24 \mu \mathrm{l}$ molecular grade water and stored at $-20^{\circ} \mathrm{C}$. All of the cDNA $(24 \mu \mathrm{l})$ was 
123 used for PCR amplification. KAPA 2G Robust HotStart Polymerase was used as the first-round

124 PCR enzyme along with the following forward primer: 5'-

125 GCCTCCCTCGCGCCATCAGAGATGTGTATAAGAGACAGNNNNTTATGGGATCAAAG

126 CCTAAAGCCATGTGTA-3' corresponding to the HIV-1 env V1/V3 region. Following

127 amplification, PCR products were purified using AmpureXP beads (Beckman Coulter) at a ratio

128 of $0.7: 1$ beads: DNA. Beads were washed four times using 70\% ethanol, and the purified DNA

129 was eluted in $50 \mu \mathrm{l}$ of DNase-free water (Corning). The second round of PCR consisted of $2 \mu 1$ of

130 purified first-round PCR product along with the KAPA HiFi Robust Polymerase enzyme and

131 served to incorporate MiSeq adaptors and index oligonucleotides that allowed for multiplexing of

132 samples.

134 MiSeq Library Preparation and Quality Control. Amplicons were visualized on a 1.2\% agarose

135 gel. Gel extraction was performed using the MinElute Gel Extraction Kit (Qiagen) according to

136 manufacturer's instructions. Purified DNA was eluted in $10 \mu \mathrm{l}$ of EB Buffer (Qiagen) and

137 quantified using the Qubit dsDNA Broad Range Assay (Thermo Fisher). Samples were pooled in

138 equimolar concentrations and the final library was purified using AmpureXP beads at a ratio of

139 0.7:1 beads: DNA. Libraries were submitted to the UNC High Throughput Sequencing Facility for

140 generation of $2 \times 300$ base paired-end reads using the Illumina MiSeq platform.

142 Phylogenetic and Compartmentalization Analyses. Compartmentalization of viral populations

143 was assessed using two tree-based methods: the Slatkin-Maddison (S-M) test (21) and the presence

144 of a genetically diverse, semen-derived lineage. The S-M test was performed on phylogenetic trees

145 that had equal numbers of semen and blood-derived V1/V3 sequences, after collapsing identical 
146 sequences in each compartment to focus on diverse populations rather than clonally amplified

147 populations. The standard Slatkin-Maddison test was modified to account for the structure of the

148 tree, with the leaves of each node being permutated sequentially before inferring migrations (Pond

149 et al, manuscript in preparation, https:/github.com/veg/hyphy-

150 analyses/tree/master/SlatkinMaddison). Trees were considered compartmentalized if 10,000

151 permutations of the Standard Slatkin-Maddison test or 50,000 permutations the Structured Slatkin-

152 Maddison test yielded a p-value $<0.05$ and there was a semen-derived, genetically diverse lineage.

153 Both S-M tests are implemented in the standard analysis "sm" in HyPhy v2.5.

Single Genome Amplification. Single genome amplification (SGA, or template end-point

156 dilution PCR) was performed as previously described (10). Briefly, viral RNA was extracted using

157 a QIAamp viral RNA extraction kit (Qiagen). cDNA was synthesized using an oligo(dT) primer

158 and SuperScript III RT (Invitrogen). Template cDNA was diluted such that $<30 \%$ of reactions

159 were positive in the subsequent PCR. Nested PCR was performed using Platinum Taq High

160 Fidelity polymerase (Invitrogen) and the following primers: PCR-1: 5'-

161 GGgttTAtTACAGGGACAGCAGAG-3' $\quad$ (Vif1) 5'-

162 TAAGCCTCAATAAAGCTTGCCTTGAGTGC-3'， (OFM19), PCR-2: 5'-

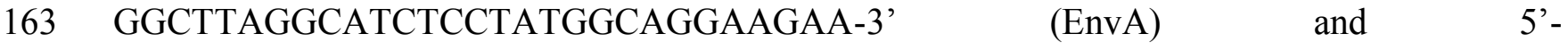

164 ACACAAGGCTACTTCCCTGGATTGGCAG-3' (EnvN). SGA products were fully sequenced

165 from both directions to confirm the presence of a single template. Amplicons with evidence of

166 multiple templates (i.e., double peaks on the chromatogram) were not used in downstream

167 applications. 
Construction of HIV-1 env clones. Amplicons of the full-length HIV-1 env gene from the first round PCR with confirmed sequences were subjected to an additional round of PCR using the

171 Phusion hot-start high fidelity DNA polymerase (Invitrogen) and the primers cEnvA (5'CACCGGCTTAGGCATCTCCTATACCAGGAAGAA-3’)

and

EnvN

$\left(5^{\prime}-\right.$

174 HIV-1 env amplicons were then gel purified using the Qiagen QIAQuick Gel Extraction Kit. An aliquot of $50 \mathrm{ng}$ of purified HIV-1 env DNA was used to clone into the pcDNA 3.1D/V5-HisTOPO vector (Invitrogen) and MAX Efficiency Stlb2 competent cells (Life Technology) per the manufacturer's instructions.

Env-pseudotyped viruses. Env-pseudotyped luciferase reporter viruses were generated by cotransfection of $810 \mathrm{ng}$ of an env expression vector and $810 \mathrm{ng}$ of pZM247Fv2 $\Delta \mathrm{env}$ backbone (22) using 293 T cells and the Fugene 6 reagent and protocol (Promega). Five hours after transfection, the medium was changed. Forty-eight hours after transfection, the medium was harvested, filtered through a $0.45 \mu \mathrm{m}$ filter, and aliquoted into $0.6 \mathrm{ml}$ tubes. Aliquots were stored at $-80^{\circ} \mathrm{C}$ until use.

Single-cycle infection of 293-Affinofile cells. The ability of HIV-1 Env proteins to mediate infection of cells expressing low densities of CD4 was assessed as previously described (23-25).

187 Briefly, experiments were carried out in black, flat-bottomed, 96-well plates. A solution of $100 \mu \mathrm{l}$ of 293-Affinofile cells at a density of $1.8 \times 10^{5}$ cells $/ \mathrm{ml}$ was added to the inner 60 wells of each 96well plate. All 293-Affinofile cells were induced to express high levels of CCR5 expression using

190 Ponesterone A. CD4 expression was induced in half of the cells using Doxycycline. Twenty-four 191 hours after CCR5 and/or CD4 induction, cells were spinoculated (26) with previously titered Env- 
192 pseudotyped viruses $\left(849 \mathrm{x}\right.$ g for 2 hours at $\left.37^{\circ} \mathrm{C}\right)$. Following spinoculation, cells were incubated 193 at $37^{\circ} \mathrm{C}$ for forty-eight hours. Cells were then washed twice with PBS and lysed with 1x Renilla

194 luciferase assay lysis buffer diluted in distilled water. Following lysis, plates were kept at $-80^{\circ} \mathrm{C}$

195 overnight. The following day, plates were thawed at room temperature and read using a

196 luminometer. A $50 \mu \mathrm{l}$ aliquot of Renilla assay reagent was injected into the luminometer per well,

197 and relative light units (RLUs) were recorded over 5 seconds with a 2-second delay.

199 Cytokine Evaluation: Cytokine concentrations in blood plasma and seminal plasma were

200 quantified using a Luminex ${ }^{\circledR}$ bead-based multiplex assay (R\&D Systems). Specifically, TNF- $\alpha$,

201 IL-6, CXCL10, IL-10, CCL2, IL-1 $\beta$, and IFN- $\gamma$ concentrations were determined. All assays were

202 performed following the manufacturer's instructions.

203

204 Data availability: The full length env gene sequences will be deposited in GenBank on

205 acceptance and the accession numbers included in proof. The MiSeq sequences will be

206 deposited in the Sequencing Read Archive and the accession numbers included in proof.

209 Results

211 Participant characteristics and sequence generation. Participants were part of a cohort of men

212 based in Malawi that was established to examine the effect of STI-associated urethritis on seminal

213 plasma HIV-1 viral load (20). In order to examine the relationship between urethritis associated

214 with a concurrent sexually transmitted infection (STI) and the presence of compartmentalized virus 
215 in the genital tract, we selected a subset of men with $(\mathrm{n}=19)$ and without $(\mathrm{n}=5)$ STI-associated

216 urethritis, with the sample size determined by availability of sufficient seminal plasma. All

217 participants were chronically infected with HIV-1, and antiretroviral therapy (ART) naive, as ART

218 was not available in Malawi at the time of the study.

219 Participant characteristics are shown in Table 1. There was no difference in the blood viral

220 load, semen viral load, or CD4+ T cell count between the two groups at baseline. HIV-1 RNA was

221 extracted from paired blood plasma and seminal plasma, and Illumina MiSeq deep sequencing

222 with Primer ID was used to generate HIV-1 env V1/V3 amplicons. The deep sequencing output

223 was collapsed into Template Consensus Sequences (TCS) for each Primer ID recovered to create

224 a highly accurate sequence for each original RNA template sampled. An average of 62 TCSs were

225 obtained from each compartment (blood and semen) for each participant (range: 12-200), giving

226 us $95 \%$ power to detect minor populations present in most samples at a $1.5-5 \%$ frequency.

Compartmentalized, semen-derived lineages are observed in men with and without

229 urethritis. As we were primarily interested in identifying diverse compartmentalized lineages,

230 which represent independent replication over a period of time, rather than compartmentalized

231 lineages that consist primarily of clonal sequences, we initially collapsed sequences that were

232 identical to within one nucleotide into a single haplotype. After identical sequences were collapsed,

233 an equal number of blood-derived and semen-derived sequences were used to construct neighbor-

234 joining phylogenetic trees for each participant, allowing us to compare the two populations at

235 equivalent sampling depth. Compartmentalization was assessed using both the Slatkin-Maddison

236 test (21), and the Structured Slatkin-Maddison test (Pond et al, in preparation,

237 https:/github.com/veg/hyphy-analyses/tree/master/SlatkinMaddison), which has been modified to 
238 reduce potentially spurious compartmentalization detection in trees with large numbers of

239 sequences. When both tests resulted in a $\mathrm{P}$ value $<0.05$, the tree was deemed compartmentalized.

240 When one test indicated compartmentalization while the other did not, trees were inspected

241 visually for the presence of diverse, semen-dominated lineages.

242 Among the 24 men, we observed varying degrees of compartmentalization, ranging from

243 near-complete separation of blood and semen-derived sequences, to minor compartmentalization

244 in 6/24 (25\%) participants. In men with urethritis, compartmentalization was detected in 5/19

245 (26\%) men, while viral populations were equilibrated between the blood and semen in 13/19(68\%)

246 men. One individual with urethritis was superinfected, with the superinfecting population

247 constituting a distinct, semen-only lineage. In men without urethritis, we observed minor

248 compartmentalization in $1 / 5(20 \%)$ individuals, and equilibrated viral populations in $4 / 5(80 \%)$

249 individuals. Thus, both compartmentalized and equilibrated HIV-1 populations were found in men

250 with and without urethritis (Figure 1 and Table 2) at statistically indistinguishable frequencies,

251 although the generalizability of this conclusion is limited by the number of samples studied.

253 HIV-1 population dynamics between blood and semen remain largely stable after STI

254 treatment. To examine the effects of antibiotic treatment of the STI on HIV-1 population

255 dynamics, we compared pre-treatment and post-treatment time points in 13 men (12 with urethritis,

2561 without urethritis). Samples were obtained an average of 12 days after antibiotic treatment had

257 been initiated (range: 7-14 days). Neighbor-joining phylogenetic trees were built as described

258 above, and the relationship between blood and semen-derived sequences (i.e., equilibrated or

259 compartmentalized) was determined at each time point. In 12/13 men, the relationship did not

260 change following STI treatment (Figure 2). In one individual, S101, semen and blood-derived 
261 lineages were equilibrated in the pre-STI treatment time point, but compartmentalized post-

262 treatment, as determined by both the Standard Slatkin-Maddison test and the Structured Slatkin-

263 Maddison test $(\mathrm{p}<0.0001$, Table 2).

264 Next, we compared within-compartment viral diversity before and after STI treatment. To

265 this end, we inferred neighbor-joining phylogenetic trees containing equal numbers of semen-

266 derived sequences from the pre and post STI treatment time points for the 13 men described above.

267 Both the Standard Slatkin-Maddison and the Structured Slatkin-Maddison tests were performed

268 on the trees in order to determine whether the pre- and post-STI treatment semen sequences

269 constituted distinct clades. In 12 of 13 men, the semen populations before and after STI treatment

270 were not significantly different from one another - i.e., populations that existed before STI

271 treatment were still readily observable after STI treatment. Of particular interest were the

272 individuals with compartmentalized, semen-derived lineages. In 2 of the 3 men with

273 compartmentalized lineages at both time points, the lineage that was responsible for the

274 compartmentalization was the same before and after STI treatment (Figure 2A and 2B). Thus, not

275 only was the relationship between compartments unchanged, but the specific lineages themselves

276 persisted. However, in one individual the compartmentalized, semen-derived lineage that was

277 detected before STI treatment was not detected at the second time point but a new

278 compartmentalized lineage was observed (Figure 2C).

280 Clonal amplification of blood and semen-derived sequences is observed in men with and

281 without urethritis. As we were primarily interested in the presence of diverse, compartmentalized

282 lineages, rather than compartmentalized lineages comprised of a clonally expanded population, we

283 collapsed sequences that were identical to within one nucleotide into a single haplotype. In doing 
so, we observed that a large proportion of both blood and semen-derived V1/V3 sequences were identical or nearly identical. Such an observation could be made because of the PCR amplification step prior to sequencing where the original templates are repetitively sequenced, a phenomenon

287 called PCR resampling; however, the use of Primer ID to tag each original templates before PCR avoids this problem allowing us to infer the presence of identical or near identical sequences within the viral population in vivo. For blood-derived sequences, a mean of only $41 \%$ and $48 \%$ of sequences were unique in men with and without urethritis, respectively $(p=0.4237$, Figure $3 \mathrm{~A})$.

291 For semen-derived sequences, a mean of only $44 \%$ and $62 \%$ of sequences were unique in men 292 with and without urethritis, respectively $(\mathrm{p}=0.086$, Figure $3 \mathrm{C})$. The proportion of unique 293 sequences observed in blood and semen remained stable before and after STI treatment in men 294 with urethritis (Figure 3B and 3D). This result indicates that a significant fraction of the population 295 in each compartment was in a genetic bottleneck or had recently gone through a bottleneck. estimate the percentage of sequences that were identical across the entirety of env. To evaluate this 298 possibility, we performed single genome amplification (SGA) of full-length HIV-1 env genes 299 ( $\sim 2500$ bases) from the blood and semen of four men ( 3 with urethritis and 1 without). We obtained an average of 30 full-length env sequences from each participant. In two of the four cases, we

301 observed identical sequences. When we trimmed the full-length sequences and analyzed only the 302 V1/V3 region used in our deep sequencing, we observed identical or nearly identical sequences in 303 all four participants. Sequences that were identical in the V1/V3 region but different across the 304 entire envelope had only a few nucleotide changes between them, consistent with the low-level 305 diversity generated from recent viral replication from a unique ancestor/bottleneck (Figure 4, and 306 Supplemental Figures 1-3). Thus, while examining only the V1/V3 region does increase the 
number of sequences that appear identical, the overall viral diversity of those variants is low and

308 consistent with recent clonal expansion involving a bottleneck with subsequent viral replication to

309 introduce modest diversity. In a control experiment we generated 8 env amplicons from virus

310 produced from the cell line $8 \mathrm{E} 5$, which contains a single defective viral genome. When the 8

311 amplicons were sequenced we observed a single substitution mutation and a single frameshift

312 mutation (data not shown). The low-level diversity observed in the viral populations in vivo were

313 in most cases greater than the level observed in the control amplification, consistent with ongoing

314 viral replication after a recent bottleneck rather than just virus production from a clonally expanded

315 cell.

317 Semen-derived HIV-1 envelopes are T-cell tropic. HIV-1 primarily infects CD4+ T cells, which

318 have a high density of the CD4 protein on their cell surface that is typically required by the virus

319 for efficient entry. However, viruses that have been replicating independently in anatomically

320 distinct regions such as the central nervous system where CD4+ T cells are less abundant, can

321 evolve the ability to enter cells expressing lower densities of CD4, such as macrophages. This has

322 been observed for compartmentalized lineages derived from both the CNS (27) and, in one case,

323 the male genital tract (28). In order to determine whether compartmentalized, semen-derived

324 lineages from our cohort have the ability to enter cells expressing a low density of CD4, we

325 performed SGA of full-length HIV-1 env genes using viral RNA as the template for cDNA

326 synthesis followed by PCR done at template end-point dilution. Amplicons were sequenced to

327 ensure that a single cDNA template initiated each amplification. A subset of the semen-derived

328 HIV-1 env gene amplicons were cloned into an expression vector then used to pseudotype a virus

329 made by cotransfecting with a $\Delta e n v$ HIV-1 backbone plasmid with a renilla luciferase reporter in 
330 order to produce pseudotyped virus that expressed participant-derived Env surface proteins.

331 Pseudotyped virus was used to infect Affinofile cells that had been induced to express either high

332 or low densities of CD4. The amount of luciferase produced by the cells was quantified and used

333 as a surrogate measure of infectivity. As shown in Figure 5, semen-derived HIV-1 env genes, from

334 both compartmentalized and equilibrated lineages, encoded Env proteins that require a high

335 density of CD4 for efficient cell entry, indicating that they were being selected for replication in T

336 cells.

338 Cytokine/chemokine dynamics during treatment of the STI. To better understand the

339 magnitude of the inflammation present within the genital tract during a concurrent sexually

340 transmitted infection, we measured the concentrations of seven inflammatory cytokines and

341 chemokines present in the blood and semen before and after treatment of the STI. To differentiate

342 between STI-induced inflammation and HIV-induced inflammation, we included samples from

343 HIV+ individuals not experiencing urethritis. As shown in Figure 6A, there was a group of

344 cytokines (TNF- $\alpha$, IL-6, and IL-1 $\beta$ ) whose concentrations were increased in the semen of men

345 with urethritis at the pre-treatment time point, and subsequently decreased after STI treatment. A

346 second group of cytokines/chemokines, including CXCL10, IL-10, IFN- $\gamma$, and CCL2, were at

347 similar concentrations in men with and without urethritis, as well as before and after STI treatment.

348 A subset of four cytokines/chemokines (TNF- $\alpha$, IL-10, CCL2 and CXCL10) were measured in

349 blood as well (Figure 6B). There was no difference in the concentration of any of these analytes at

350 any time point in men with or without urethritis, suggesting that STI-associated inflammation is

351 limited to the genital tract and largely resolves with antibiotic treatment. 


\section{Identification and characterization of a super-infection initiated in the male genital tract. In}

354 one participant with urethritis, S031, we observed a distinct, semen-only lineage in both the pre355 and post-STI treatment time points (Figure 7A). Though the separate, semen-only lineage persisted

356 across two time points, we did note that fewer semen-derived sequences were in semen-only clades

357 in the second time point (post-STI treatment) as compared to the first time point (pre-STI

358 treatment), suggesting that viral populations in the blood had been mixing with viral populations

359 in the genital tract. Importantly, we observed semen-derived sequences that clustered with the

360 blood-derived sequences at both time points, thus making contamination or sample mis-labeling

361 an unlikely explanation for our observation (Figure 7A). When we constructed a neighbor-joining

362 phylogenetic tree using blood- and semen-derived sequences from this participant and four others,

363 we noted that the semen-derived sequences from S031 were as distinct from the blood-derived

364 sequences as all participants were from one another, suggesting the presence of a superinfection

365 (Figure 7B). A highlighter plot was used to identify the presence of recombinant lineages within

366 the blood- and semen-derived sequences (Figure 7C), further supporting the notion of 367 superinfection.

370 Discussion

There have been numerous studies $(12-14,29-33)$ that have examined the prevalence of

373 male genital tract compartmentalization of HIV-1, sometimes with discordant results. Some of

374 these studies $(11,29,30)$ examined the phenomenon of compartmentalization through the use of

375 bulk amplification and/or cloning prior to sequencing; however these approaches have been shown 
to introduce sequencing artifacts, such as PCR-mediated recombination and sequence resampling (34-36). The use of deep sequencing with Primer ID in the current study corrects for PCR and sequencing errors through the creation of a template consensus sequence for each Primer IDtagged cDNA (the template for PCR), while simultaneously allowing for the precise quantification of the total number of templates sequenced, i.e. the sample size of sampling of the viral sequence population (19). Thus, we can be confident that the viral variants we analyze are an accurate representation of the diversity found in vivo.

The observation that STI-associated urethritis does not significantly impact the degree of

384 HIV-1 compartmentalization within the male genital tract raises several points. First, the mechanism underlying the establishment of compartmentalized lineages within the male genital tract remains unknown. This study sought to compare two possibilities: that STI-associated inflammation would lead to compartmentalized replication, or alternatively serve to recruit HIVinfected CD4+ T cells into the genital tract, thereby equilibrating the viral populations found in the blood and semen. We observed compartmentalization in $26 \%$ of men with urethritis, and $20 \%$ of men without urethritis; thus, given this number of participants we did not detect a difference in

391 the extent of compartmentalization with and without and STI-associated urethritis. In the overall 392 cohort, we observed compartmentalization in the genital tract of $25 \%$ of men. This prevalence of 393 compartmentalized lineages in the genital tract is similar to what was observed in a previous study

394 (9) that used a heteroduplex tracking assay to examine the relationship between blood and semen395 derived env V3 populations in men with and without urethritis. In this earlier study, they observed 396 discordant V3 populations between the blood and semen of $40 \%$ of men. Importantly, there was 397 no difference in the V3 population dynamics between the blood and semen of men with urethritis, 398 compared to men without urethritis. Later, Anderson and colleagues (10) utilized single genome 
amplification to examine the relationship between blood and semen-derived HIV-1 envelopes in

400 men without urethritis. Here, they reported a $31 \%$ prevalence of compartmentalization in the

401 genital tract. They also observed clonal amplification in the semen of men without urethritis.

402 Compartmentalized populations in the genital tract have also been observed in the context of acute

403 HIV-1 infection. In a recent study by Chaillon et al. (31), deep sequencing was used to examine

404 HIV-1 populations in blood and semen in early infection. They observed compartmentalization in 4052 of 6 participants at baseline (a median of 81 days after the estimated date of infection).

The second noteworthy point pertains to the source of HIV-1 shed in the semen. HIV-1

$407(12,13,37)$ and/or SIV (38) RNA has been recovered from a variety of male genital tract tissues

408 including the urethra, prostate, testis, seminal vesicles, vas deferens and epididymis. Our

409 observation that inflammation does not alter the frequency with which we detect semen-specific

410 HIV-1 lineages suggests that, when compartmentalized lineages are present, they are most likely

411 produced by cells in anatomical areas that are not in direct contact with the periphery. In one

412 extreme case of this type of isolation we previously observed the presence of a macrophage-tropic

413 variant in semen (28) which suggests that in this case there was sufficient depletion of CD4+ T

414 cells, without replenishment, that the virus evolved to expand its target cell specificity. In the

415 current study all of the viruses tested were $\mathrm{T}$ cell-tropic, requiring a high density of CD4 for

416 efficient entry into cells. In addition, all were predicted to use CCR5 as a coreceptor based on

417 genotypic predictions of the V3 loop sequence (data not shown). This result is important as a recent

418 report by Ganor and colleagues (39) reported the presence of macrophage-tropic viral variants in

419 urethral tissues, suggesting the possibility of a urethral reservoir. However, it appears such variants

420 are not shed in the semen. 
422 transient phenomenon. Here, we examined how antibiotic treatment of a concurrent sexually

423 transmitted infection (primarily gonorrhea or trichomonas) impacted the relationship between

424 blood- and semen-derived HIV-1 env V1/V3 sequences. We found that viral variants present

425 before STI treatment remained detectable after STI treatment, and furthermore, that the

426 relationship between blood and semen-derived sequences remained consistent throughout the

427 course of STI co-infection. In only one participant out of 13 did we detect a change in the

428 relationship between blood and semen-derived sequences over time. In this instance, the depth of

429 sampling pre-STI treatment was relatively poor, with only $13 \mathrm{~V} 1 / \mathrm{V} 3$ sequences recovered per

430 compartment, while the sampling post-STI treatment was much greater (103 sequences per

431 compartment). Thus, it is quite possible that the relatively few sequences obtained pre-treatment

432 obscured the presence of the compartmentalized lineage that we observed post-treatment. It is also

433 important to note that while gonococcal infections are cleared rapidly from the urogenital tract

434 after a single antibiotic treatment (40), the underlying immune activation can persist, as

435 demonstrated by the fact that in men with an STI, HIV-1 viral loads in semen were still higher

436 than in men without an STI, even after effective antibiotic treatment (20), although we were able

437 to measure some diminution of inflammation with a change in some inflammatory markers.

438 Therefore, while we do observe stable relationships between blood and semen-derived sequences

439 both before and after STI treatment, our conclusions are limited by the relatively short period of

440 follow-up. It is worth noting that in one participant, virus in the semen was compartmentalized

441 relative to the blood both before and after STI treatment but the compartmentalized lineage in the

442 semen changed between the two time points. Both lineages, while minor, were complex in

443 sequence composition and thus the latter one did not evolve over the short period of time between 
444 the two samplings. Thus, there must have been reduced production of one lineage and the 445 appearance of a pre-existing lineage over a relatively short period of time.

447 transmitted/founder viral variant rapidly evolves into a diverse population within an infected 448 individual (42-44). As such, the identification of identical or nearly identical sequences in the 449 blood in chronic untreated infection is relatively infrequent. There are two mechanisms to consider 450 that can explain the presence of such sequences. In people on therapy there can be low level 451 production of virus particles with identical sequences and this is thought to be due to clonal 452 expansion of an infected cell (45-47) some of which can produce a low level of infectious virus $453(48,49)$. In the absence of therapy, the viral load of viruses with similar sequences is much higher, 454 suggesting either that the corresponding cellular expansion is much greater or that the virus comes 455 from another source, i.e. replication, after passing through a recent genetic bottleneck. This 456 question becomes even more relevant using the shorter amplicon associated with deep sequencing 457 as a significant fraction of the viral sequences cluster into lineages of identical sequences. In order 458 to determine if the identical sequences from deep sequencing observed off therapy in these men 459 were truly clonal, we compared sequences obtained from deep sequencing to those obtained as full 460 length env genes using template end-point dilution PCR (SGA). We found that the sequences that 461 were identical in the deep sequencing data set were in a population of similar but not identical 462 sequences when the larger region of the genome was analyzed (Figure 4, Supplemental Figure 1463 3). We conclude that these populations are present at their detected level due to ongoing viral 464 replication. However, the high level of similarity in these sequences implies a recent genetic 465 bottleneck prior to expansion by viral replication, although the nature of that bottleneck remains 466 unknown and could still be due to clonal expansion of an infected cell amplified by a burst of local 
467 replication. It is possible that this phenomenon is mediated by an infected antigen-specific cell that 468 undergoes amplification due to the presence of the STI. HIV-1 infection is associated with dysregulation of seminal cytokines $(50,51)$ as well as

470 an increased semen: blood cytokine ratio $(10,50,51)$. This pro-inflammatory environment has

471 been suggested to increase viral replication as semen viral load often correlates with cytokine

472 levels (52), as well as the fact that several cytokines, including TNF- $\alpha$, directly act on the virus to 473 increase replication (53) (reviewed in (54)). A similar phenomenon is observed in men with 474 classical STIs such as gonorrhea or trichomonas (20). We analyzed cytokine/chemokine levels in 475 the blood and semen of men with and without STI-associated urethritis to determine if 476 inflammation increased with the presence of a concurrent STI infection and whether such 477 inflammation had resolved during the two-week period of follow-up. Among the seven 478 cytokines/chemokines analyzed (IL-6, TNF- $\alpha$, IL-1 $\beta$, IFN- $\gamma$, CXCL10, IL-10 and CCL2) only 479 TNF- $\alpha$ was significantly increased in the semen of men with STI-associated urethritis, compared 480 to HIV-positive men without urethritis. However, levels of IL-6 and IL-1 $\beta$ were also increased in 481 men with urethritis, though the difference was not statistically significant. Importantly, the levels 482 of TNF- $\alpha$, IL-6 and IL-1 $\beta$ all decreased to levels similar to that of men without urethritis after STI 483 treatment. Thus, we observed that men with urethritis have an enhanced pro-inflammatory 484 environment compared to HIV-positive men without urethritis, and that this difference is reduced 485 following antibiotic treatment of the STI. As expected, cytokine levels in the blood were similar 486 in men with and without STI-associated urethritis and remained unchanged following STI 487 treatment. This result further supports our finding that inflammation due to STI-associated 488 urethritis does not impact the formation of compartmentalized lineages in the male genital tract. 


\section{Acknowledgements}

491 We would like to acknowledge all participants. We would also like to thank Li-Hua Ping for her

492 help in organizing the samples and data. This work was supported by NIH award

493 5R01DK108424-05 to MSC, and by R01AI140970 to RS. ODC was supported by NIH training

494 grant T32-AI007001. The work was also supported by the UNC Center For AIDS Research

495 (NIH award P30 AI50410) and the UNC Lineberger Comprehensive Cancer Center (NIH award

496 P30 CA16068). We wish to acknowledge the efforts of the UNC High Throughput Sequencing

497 Facility. Competing interests: UNC is pursuing IP protection for Primer ID, and RS is listed as

498 a co-inventor and has received nominal royalties. 


\section{References}

514 1. UNAIDS. 2019. UNAIDS Global AIDS Update 2019.

515 2. Quinn TC, Wawer MJ, Sewankambo N, Serwadda D, Li C, Wabwire-Mangen F, Meehan

516 MO, Lutalo T, Gray RH. 2000. Viral load and heterosexual transmission of human

517 immunodeficiency virus type 1. Rakai Project Study Group. N Engl J Med 342:921-929.

518 3. Gray RH, Wawer MJ, Brookmeyer R, Sewankambo NK, Serwadda D, Wabwire-Mangen

519 F, Lutalo T, Li X, vanCott T, Quinn TC, Rakai Project T. 2001. Probability of HIV-1

520 transmission per coital act in monogamous, heterosexual, HIV-1-discordant couples in

$521 \quad$ Rakai, Uganda. Lancet 357:1149-1153.

522 4. Wawer MJ, Gray RH, Sewankambo NK, Serwadda D, Li X, Laeyendecker O, Kiwanuka

523 N, Kigozi G, Kiddugavu M, Lutalo T, Nalugoda F, Wabwire-Mangen F, Meehan MP,

524 Quinn TC. 2005. Rates of HIV-1 transmission per coital act, by stage of HIV-1 infection,

525 in Rakai, Uganda. J Infect Dis 191:1403-1409.

526 5. Baeten JM, Kahle E, Lingappa JR, Coombs RW, Delany-Moretlwe S, Nakku-Joloba E,

527 Mugo NR, Wald A, Corey L, Donnell D, Campbell MS, Mullins JI, Celum C, Partners in

528 Prevention HSVHIVTST. 2011. Genital HIV-1 RNA predicts risk of heterosexual HIV-1

$529 \quad$ transmission. Sci Transl Med 3:77ra29.

$530 \quad 6 . \quad$ de Vincenzi I. 1994. A longitudinal study of human immunodeficiency virus transmission 531 by heterosexual partners. European Study Group on Heterosexual Transmission of HIV.

$532 \quad$ N Engl J Med 331:341-346.

533 7. Dyer JR, Eron JJ, Hoffman IF, Kazembe P, Vernazza PL, Nkata E, Costello Daly C,

534 Fiscus SA, Cohen MS. 1998. Association of CD4 cell depletion and elevated blood and 
seminal plasma human immunodeficiency virus type 1 (HIV-1) RNA concentrations with genital ulcer disease in HIV-1-infected men in Malawi. J Infect Dis 177:224-227.

537 8. Galvin SR, Cohen MS. 2004. The role of sexually transmitted diseases in HIV transmission. Nat Rev Microbiol 2:33-42.

9. Ping LH, Cohen MS, Hoffman I, Vernazza P, Seillier-Moiseiwitsch F, Chakraborty H, Kazembe P, Zimba D, Maida M, Fiscus SA, Eron JJ, Swanstrom R, Nelson JA. 2000. Effects of genital tract inflammation on human immunodeficiency virus type $1 \mathrm{~V} 3$ populations in blood and semen. J Virol 74:8946-8952.

10. Anderson JA, Ping LH, Dibben O, Jabara CB, Arney L, Kincer L, Tang Y, Hobbs M, Hoffman I, Kazembe P, Jones CD, Borrow P, Fiscus S, Cohen MS, Swanstrom R, Center for HIVAVI. 2010. HIV-1 Populations in Semen Arise through Multiple Mechanisms.

547 11. Gupta P, Leroux C, Patterson BK, Kingsley L, Rinaldo C, Ding M, Chen Y, Kulka K, Buchanan W, McKeon B, Montelaro R. 2000. Human immunodeficiency virus type 1 shedding pattern in semen correlates with the compartmentalization of viral Quasi species between blood and semen. J Infect Dis 182:79-87.

551 12. Coombs RW, Lockhart D, Ross SO, Deutsch L, Dragavon J, Diem K, Hooton TM, Collier AC, Corey L, Krieger JN. 2006. Lower genitourinary tract sources of seminal HIV. J Acquir Immune Defic Syndr 41:430-438.

554 13. Diem K, Nickle DC, Motoshige A, Fox A, Ross S, Mullins JI, Corey L, Coombs RW, virus type 1 (HIV). AIDS Res Hum Retroviruses 24:561-571. 
557 14. Gianella S, Mehta SR, Strain MC, Young JA, Vargas MV, Little SJ, Richman DD,

558 Kosakovsky Pond SL, Smith DM. 2012. Impact of seminal cytomegalovirus replication

559 on HIV-1 dynamics between blood and semen. J Med Virol 84:1703-1709.

560 15. Delwart EL, Mullins JI, Gupta P, Learn GH, Jr., Holodniy M, Katzenstein D, Walker BD, Singh MK. 1998. Human immunodeficiency virus type 1 populations in blood and

16. Pasquier C, Walschaerts M, Raymond S, Moinard N, Saune K, Daudin M, Izopet J, Bujan L. 2017. Patterns of residual HIV-1 RNA shedding in the seminal plasma of patients on effective antiretroviral therapy. Basic Clin Androl 27:17.

17. Politch JA, Mayer KH, Welles SL, O'Brien WX, Xu C, Bowman FP, Anderson DJ. 2012. Highly active antiretroviral therapy does not completely suppress HIV in semen of

19. Zhou S, Jones C, Mieczkowski P, Swanstrom R. 2015. Primer ID Validates Template sexually active HIV-infected men who have sex with men. AIDS 26:1535-1543.

18. Jabara CB, Jones CD, Roach J, Anderson JA, Swanstrom R. 2011. Accurate sampling and deep sequencing of the HIV-1 protease gene using a Primer ID. Proc Natl Acad Sci 
579 21. Slatkin M, Maddison WP. 1989. A cladistic measure of gene flow inferred from the

$580 \quad$ phylogenies of alleles. Genetics 123:603-613.

581 22. Ping LH, Joseph SB, Anderson JA, Abrahams MR, Salazar-Gonzalez JF, Kincer LP, 582 Treurnicht FK, Arney L, Ojeda S, Zhang M, Keys J, Potter EL, Chu H, Moore P, Salazar

23. Joseph SB, Lee B, Swanstrom R. 2014. Affinofile Assay for Identifying MacrophageTang Y, Labranche C, Lee B, Saville A, Vermeulen M, Fiscus S, Morris L, Karim SA, Haynes BF, Shaw GM, Korber BT, Hahn BH, Cohen MS, Montefiori D, Williamson C, Swanstrom R, Study CAI, the Center for HIVAVIC. 2013. Comparison of viral Env proteins from acute and chronic infections with subtype $\mathrm{C}$ human immunodeficiency Tropic HIV-1. Bio Protoc 4.

24. Lee B, Sharron M, Montaner LJ, Weissman D, Doms RW. 1999. Quantification of CD4, CCR5, and CXCR4 levels on lymphocyte subsets, dendritic cells, and differentially conditioned monocyte-derived macrophages. Proc Natl Acad Sci U S A 96:5215-5220.

598 26. O'Doherty U, Swiggard WJ, Malim MH. 2000. Human immunodeficiency virus type 1 599 spinoculation enhances infection through virus binding. J Virol 74:10074-10080.

600 27. Schnell G, Joseph S, Spudich S, Price RW, Swanstrom R. 2011. HIV-1 replication in the central nervous system occurs in two distinct cell types. PLoS Pathog 7:e1002286. 
602 28. Bednar MM, Hauser BM, Ping LH, Dukhovlinova E, Zhou S, Arrildt KT, Hoffman IF,

603 Eron JJ, Cohen MS, Swanstrom R. 2015. R5 Macrophage-Tropic HIV-1 in the Male

604 Genital Tract. J Virol 89:10688-10692.

605 29. Paranjpe S, Craigo J, Patterson B, Ding M, Barroso P, Harrison L, Montelaro R, Gupta P. 2002. Subcompartmentalization of HIV-1 quasispecies between seminal cells and seminal plasma indicates their origin in distinct genital tissues. AIDS Res Hum

30. Chaillon A, Gianella S, Wertheim JO, Richman DD, Mehta SR, Smith DM. 2014. HIV migration between blood and cerebrospinal fluid or semen over time. J Infect Dis 209:1642-1652.

31. Chaillon A, Smith DM, Vanpouille C, Lisco A, Jordan P, Caballero G, Vargas M, Untreated HIV Infection. J Acquir Immune Defic Syndr 74:95-102.

32. Cheret A, Durier C, Melard A, Ploquin M, Heitzmann J, Lecuroux C, Avettand-Fenoel V,

619 33. Boeras DI, Hraber PT, Hurlston M, Evans-Strickfaden T, Bhattacharya T, Giorgi EE, donor genital tract HIV-1 diversity in the transmission bottleneck. Proc Natl Acad Sci U

623 34. Meyerhans A, Vartanian JP, Wain-Hobson S. 1990. DNA recombination during PCR. Nucleic Acids Res 18:1687-1691. 
625 35. Salazar-Gonzalez JF, Bailes E, Pham KT, Salazar MG, Guffey MB, Keele BF, Derdeyn

626 CA, Farmer P, Hunter E, Allen S, Manigart O, Mulenga J, Anderson JA, Swanstrom R,

627 Haynes BF, Athreya GS, Korber BT, Sharp PM, Shaw GM, Hahn BH. 2008. Deciphering

628 human immunodeficiency virus type 1 transmission and early envelope diversification by

629 single-genome amplification and sequencing. J Virol 82:3952-3970.

630 36. Liu SL, Rodrigo AG, Shankarappa R, Learn GH, Hsu L, Davidov O, Zhao LP, Mullins

631 JI. 1996. HIV quasispecies and resampling. Science 273:415-416.

632 37. Houzet L, Matusali G, Dejucq-Rainsford N. 2014. Origins of HIV-infected leukocytes and virions in semen. J Infect Dis 210 Suppl 3:S622-30.

634 38. Houzet L, Perez-Losada M, Matusali G, Deleage C, Dereuddre-Bosquet N, Satie AP, Aubry F, Becker E, Jegou B, Le Grand R, Keele BF, Crandall KA, Dejucq-Rainsford N.

39. Ganor Y, Real F, Sennepin A, Dutertre CA, Prevedel L, Xu L, Tudor D, Charmeteau B, Couedel-Courteille A, Marion S, Zenak AR, Jourdain JP, Zhou Z, Schmitt A, Capron C, Eugenin EA, Cheynier R, Revol M, Cristofari S, Hosmalin A, Bomsel M. 2019. HIV-1 reservoirs in urethral macrophages of patients under suppressive antiretroviral therapy.

643 40. Haizlip J, Isbey SF, Hamilton HA, Jerse AE, Leone PA, Davis RH, Cohen MS. 1995. Time required for elimination of Neisseria gonorrhoeae from the urogenital tract in men with symptomatic urethritis: comparison of oral and intramuscular single-dose therapy. 
647 41. Mansky LM, Temin HM. 1995. Lower in vivo mutation rate of human immunodeficiency virus type 1 than that predicted from the fidelity of purified reverse transcriptase. $\mathrm{J}$ Virol

650 42. Keele BF, Giorgi EE, Salazar-Gonzalez JF, Decker JM, Pham KT, Salazar MG, Sun C,

43. Joseph SB, Swanstrom R, Kashuba AD, Cohen MS. 2015. Bottlenecks in HIV-1

44. Goonetilleke N, Liu MK, Salazar-Gonzalez JF, Ferrari G, Giorgi E, Ganusov VV, Keele Haynes BF, Cohen MS, Hraber P, Bhattacharya T, Borrow P, Perelson AS, Hahn BH, Shaw GM, Korber BT, McMichael AJ. 2009. The first T cell response to

665 45. Maldarelli F, Wu X, Su L, Simonetti FR, Shao W, Hill S, Spindler J, Ferris AL, Mellors 
669 46. Wagner TA, McLaughlin S, Garg K, Cheung CY, Larsen BB, Styrchak S, Huang HC, Edlefsen PT, Mullins JI, Frenkel LM. 2014. HIV latency. Proliferation of cells with HIV integrated into cancer genes contributes to persistent infection. Science 345:570-573.

672 47. Cohn LB, Silva IT, Oliveira TY, Rosales RA, Parrish EH, Learn GH, Hahn BH, Czartoski JL, McElrath MJ, Lehmann C, Klein F, Caskey M, Walker BD, Siliciano JD,

48. Simonetti FR, Sobolewski MD, Fyne E, Shao W, Spindler J, Hattori J, Anderson EM, Watters SA, Hill S, Wu X, Wells D, Su L, Luke BT, Halvas EK, Besson G, Penrose KJ, Yang Z, Kwan RW, Van Waes C, Uldrick T, Citrin DE, Kovacs J, Polis MA, Rehm CA, Gorelick R, Piatak M, Keele BF, Kearney MF, Coffin JM, Hughes SH, Mellors JW,

49. Wang Z, Gurule EE, Brennan TP, Gerold JM, Kwon KJ, Hosmane NN, Kumar MR, Beg

50. Vanpouille C, Introini A, Morris SR, Margolis L, Daar ES, Dube MP, Little SJ, Smith DM, Lisco A, Gianella S. 2016. Distinct cytokine/chemokine network in semen and and reprogrammed cytokine network. J Infect Dis 205:97-105. 
692 52. Osborne BJW, Marsh AK, Huibner S, Shahabi K, Liu C, Contente T, Nagelkerke NJD,

693 Kovacs C, Benko E, Price L, MacDonald KS, Kaul R. 2017. Clinical and Mucosal

694 Immune Correlates of HIV-1 Semen Levels in Antiretroviral-Naive Men. Open Forum

695 Infect Dis 4:ofx033.

696 53. Kinter AL, Poli G, Fox L, Hardy E, Fauci AS. 1995. HIV replication in IL-2-stimulated

697 peripheral blood mononuclear cells is driven in an autocrine/paracrine manner by

698 endogenous cytokines. J Immunol 154:2448-2459.

699 54. Pasquereau S, Kumar A, Herbein G. 2017. Targeting TNF and TNF Receptor Pathway in 700 HIV-1 Infection: from Immune Activation to Viral Reservoirs. Viruses 9. 


\begin{tabular}{|c|c|c|c|c|c|c|}
\hline & \multicolumn{2}{|c|}{ Before STI Treatment } & \multicolumn{2}{|c|}{ After STI Treatment } & \multirow[b]{2}{*}{ CD4 Count ${ }^{\mathrm{a}}$} & \multirow[b]{2}{*}{ Diagnosed STI } \\
\hline & $\begin{array}{c}\text { Plasma Viral } \\
\text { Load } \\
\left(\log _{10} \text { copies } / \mathrm{mL}\right)\end{array}$ & $\begin{array}{c}\text { Semen } \\
\text { Viral Load } \\
\left(\log _{10}\right. \\
\text { copies } / \mathbf{m L}) \\
\end{array}$ & $\begin{array}{c}\text { Plasma Viral } \\
\text { Load } \\
\left(\log _{10} \text { copies } / \mathrm{mL}\right)\end{array}$ & $\begin{array}{l}\text { Semen Viral Load } \\
\text { (copies/mL) }\end{array}$ & & \\
\hline \multicolumn{7}{|l|}{ Urethritis $(n=19)$} \\
\hline S003 & 5.23 & 5.48 & 5.51 & 4.8 & ND & Gon., Ulc \\
\hline S018 & 5.59 & 4.70 & 5.40 & 4.96 & 476 & Gon, Tri, Ulc \\
\hline S019 & 4.18 & 5.48 & 4.34 & 4.32 & 712 & Gon \\
\hline S031 & 4.95 & 4.62 & 4.63 & 4.92 & 333 & Gon, Ulc \\
\hline S053 & 6.11 & 6.08 & 5.88 & 5.38 & 318 & Tri, Ulc \\
\hline S070 & 4.73 & 3.92 & 4.96 & 4.46 & 670 & Gon \\
\hline S073 & 4.59 & 4.60 & 4.51 & 4.23 & 275 & Gon \\
\hline S075 & 5.59 & 5.20 & 5.90 & 4.08 & ND & NPI \\
\hline S101 & 5.83 & 5.89 & 5.79 & 5.20 & 235 & Gon \\
\hline S103 & 3.95 & 5.00 & 5.11 & 4.79 & 454 & Gon \\
\hline S146 & 4.79 & 4.96 & 5.58 & 5.53 & 258 & Ulc \\
\hline S172 & 4.80 & 5.18 & 4.28 & 4.62 & 344 & Gon \\
\hline S029 & 5.23 & 4.71 & ND & ND & 496 & Gon \\
\hline S017 & 5.79 & 4.40 & ND & ND & 178 & NPI \\
\hline S039 & 5.56 & 5.04 & ND & ND & ND & Gon \\
\hline S047 & 5.77 & 4.92 & ND & ND & 469 & Gon \\
\hline S099 & 5.57 & 5.82 & ND & ND & ND & Gon, Tri \\
\hline $\mathrm{S} 148$ & 5.08 & 5.98 & ND & ND & & Gon \\
\hline S067 & 4.90 & 5.04 & ND & ND & & Gon \\
\hline \multicolumn{7}{|l|}{ No Urethritis $(n=5)$} \\
\hline $\mathrm{C} 019$ & 7.00 & 5.72 & 5.72 & 6.76 & 599 & None \\
\hline $\mathrm{C} 073$ & 4.82 & 3.76 & ND & ND & ND & None \\
\hline $\mathrm{C} 082$ & 5.49 & 4.20 & ND & ND & 305 & None \\
\hline C111 & 4.84 & 5.95 & ND & ND & 210 & None \\
\hline $\mathrm{C} 061$ & 5.56 & 6.51 & ND & ND & 262 & None \\
\hline
\end{tabular}

Table 1. Relevant clinical information for the particpants analyzed. aCells per microliter of blood. 'Diagnosed STI. Gon, gonorrhea; Tri, trichomonas; Ulc, genital ulcers; NPI, no pathogen identified. ND, not done. 


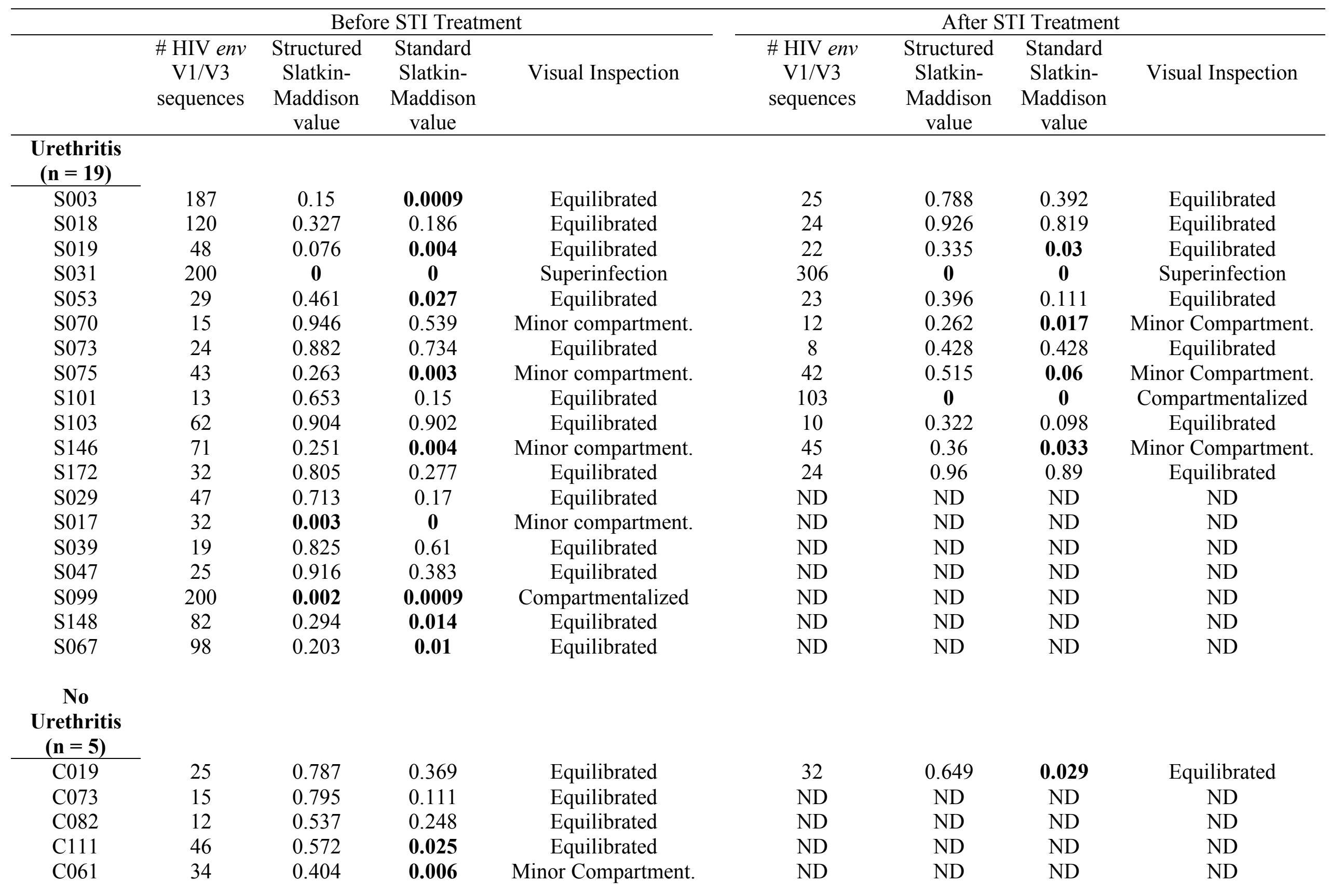

Table 2. Summary of the methods used to determine the relationship between blood-derived and semen-derived HIV-1 env V1/V3 sequences. Bolded values indicate statistically significant compartmentalization as determined by the indicated method. 
Figure 1. Representative neighbor-joining env V1/V3 phylogenetic trees depicting compartmentalization between the blood and semen-derived lineages (A) and equilibration between blood and semen-derived lineages (B). Blood-derived sequences are shown in red, semen-derived sequences are shown in blue. Circles indicate compartmentalized nodes.

Figure 2. HIV-1 population dynamics between blood and semen remain unchanged after STI treatment. Neighbor-joining phylogenetic trees depicting blood-derived env V1/V3 sequences (shades of red) and semen-derived env V1V3 sequences (shades of blue). Sequences from before and after STI treatment are shown. In (A) and (B), the same compartmentalized lineage appears in the semen before and after STI treatment (circled nodes). In (C), a different semen-derived, compartmentalized lineage is observed in the pre and post STI-treatment time points.

Figure 3. Clonal amplification of identical sequences is observed in both blood and semenderived viruses in men with and without urethritis. An analysis of the percent of V1/V3 sequences that are not identical, derived from blood (A), or semen (C). The percent of unique sequences remains stable in overtime in both the blood (B) and semen (D). An unpaired t test was used to generate the indicated $p$ values.

Figure 4. Highlighter plot of paired full-length $e n v$ and $e n v \mathrm{V1} / \mathrm{V} 3$ sequences. SGA-derived full-length envelope sequences and the corresponding V1/V3 region only are shown on the left and right, respectively. Boxed sequences represent those that are identical in the V1/V3 amplicon, and nearly identical over the full envelope amplicon.

Figure 5. SGA-derived HIV-1 envelopes from the semen are T-cell tropic. (A-C) Neighborjoining trees of env V1/V3 blood (red) and semen (blue) derived sequences. The graphs below depicts the ability of SGA-derived envelopes from blood and semen to enter cells expressing low densities of CD4. Colored arrows on the trees depict the locations of the envelopes used in the graphs below. JR-CSF and Bal are T-tropic and M-tropic controls, respectively. Data represent the average of three biological replicates.

Figure 6. Cytokine/chemokine analysis in semen and blood before and after antibiotic treatment of the STI. Cytokine/chemokine concentrations in semen (A) and blood (B) were measured before and after STI treatment. The values were compared to a group of HIV+ men without a concurrent STI (labeled as "control", and depicted by the grey bars). A one-way ANOVA was used to generate the indicated $p$ value.

Figure 7. Characterization of a super-infection. A) Pre and post-STI treatment neighborjoining phylogenetic trees depicting a distinct semen-only lineage from participant S031. Semenderived sequences are shown in blue, blood-derived sequences are shown in red. The percent of all semen-derived sequences that cluster independently from the blood is shown at the bottom. B) A neighbor-joining phylogenetic tree containing blood and semen-derived sequences from five participants. Sequences from each participant are shown in a different color, sequences from S031 are purple. C) Highlighter plot depicting recombination between blood and semen-derived sequences from S031. 
bioRxiv preprint doi: https://doi.org/10.1101/2020.01.28.924225; this version posted January 29, 2020. The copyright holder for this preprint (which was not certified by peer review) is the author/funder. All rights reserved. No reuse allowed without permission.

A.

Compartmentalized

\section{S017}

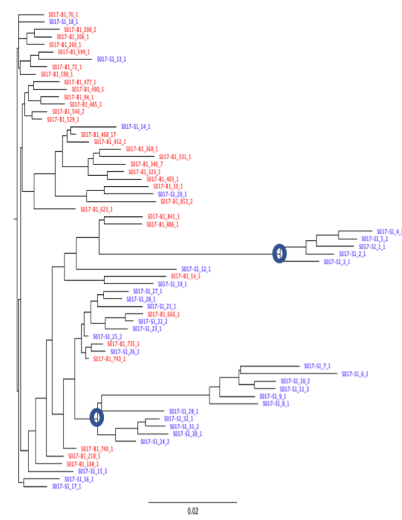

S075

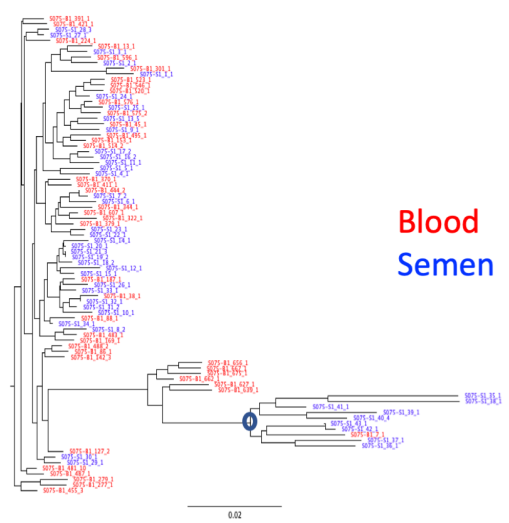

B.

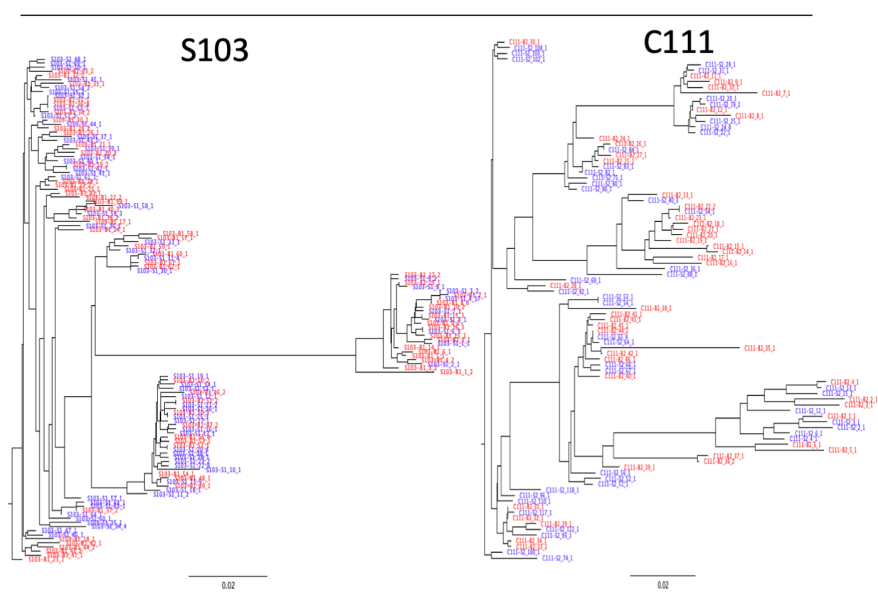

Figure 1. Representative neighbor-joining env V1/V3 phylogenetic trees depicting compartmentalization between the blood and semen-derived lineages (A) and equilibration between blood and semen-derived lineages (B). Blood-derived sequences are shown in red, semen-derived sequences are shown in blue. Circles indicate compartmentalized nodes. 
A. S146

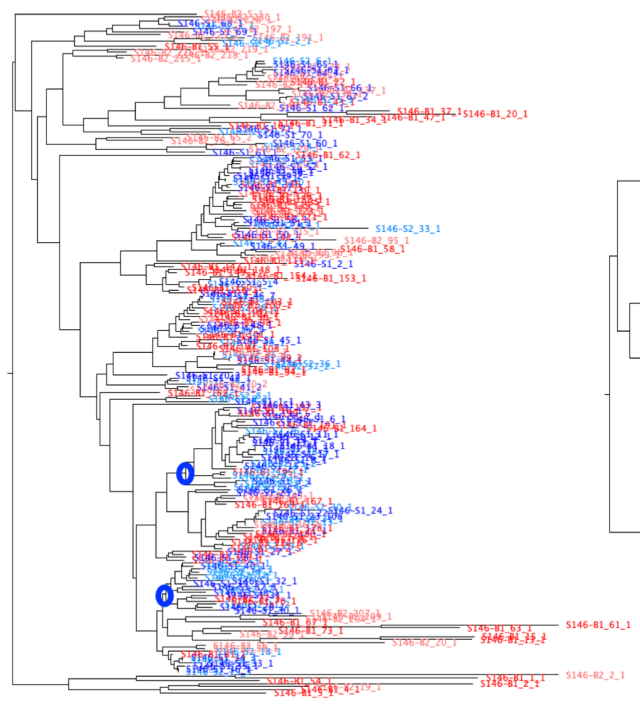

$\longrightarrow 0.02$
B.

S070

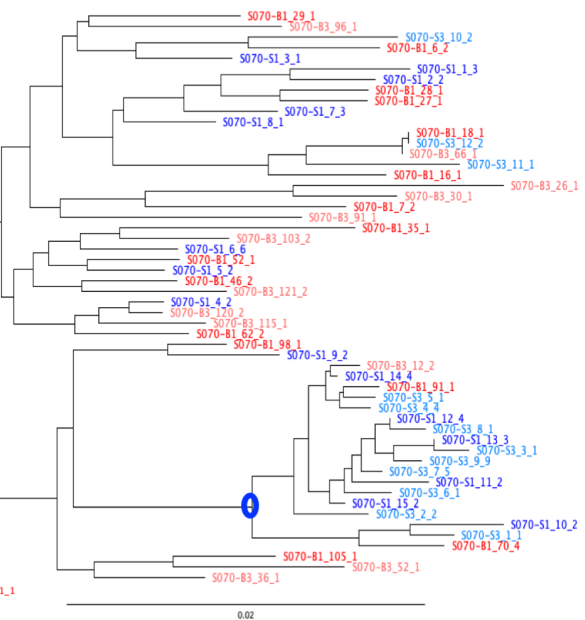

C.

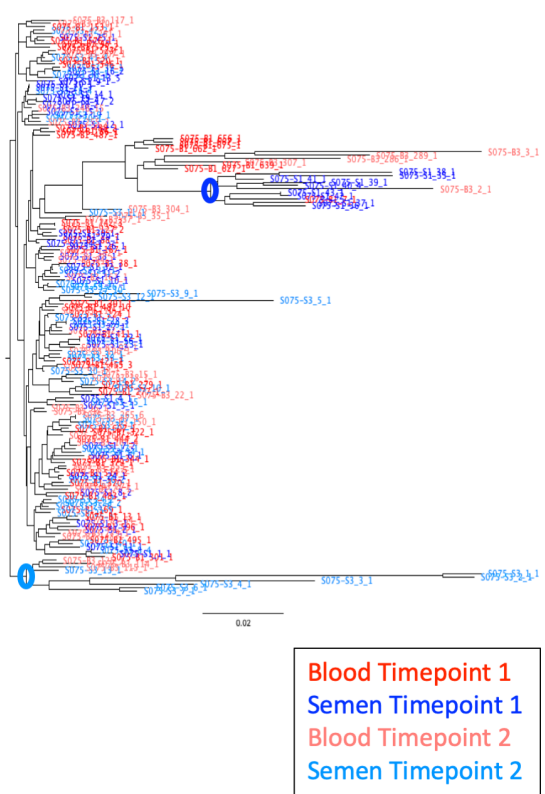

Figure 2. HIV-1 population dynamics between blood and semen remain unchanged after STI treatment. Neighbor-joining phylogenetic trees depicting blood-derived env V1/V3 sequences (shades of red) and semenderived env V1V3 sequences (shades of blue). Sequences from before and after STI treatment are shown. In (A) and (B), the same compartmentalized lineage appears in the semen before and after STI treatment (circled nodes). In (C), a different semen-derived, compartmentalized lineage is observed in the pre and post STItreatment time points. 

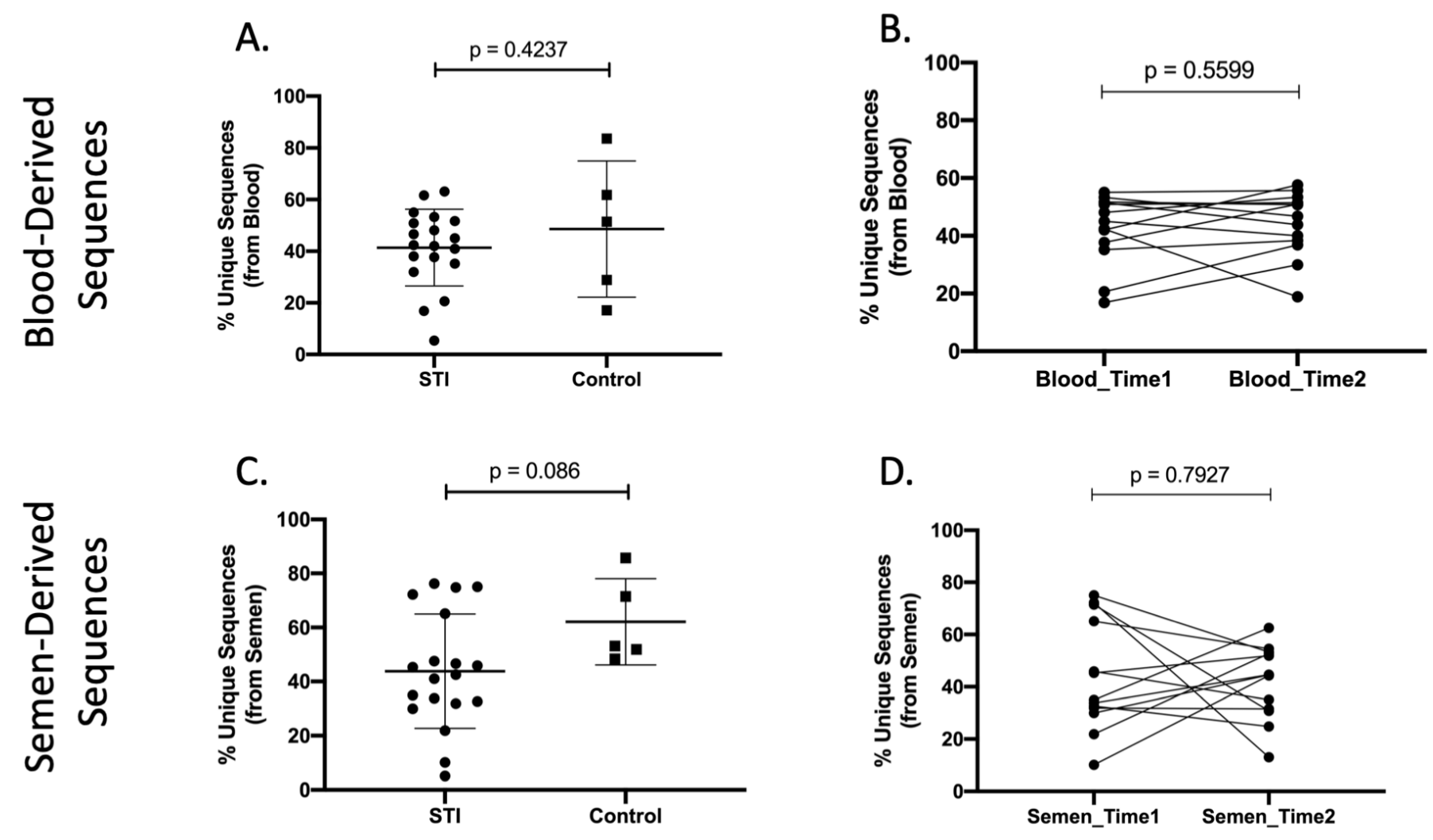

Figure 3. Clonal amplification of identical sequences is observed in both blood and semen-derived viruses in men with and without urethritis. An analysis of the percent of $\mathrm{V} 1 / \mathrm{V} 3$ sequences that are not identical, derived from blood (A), or semen (C). The percent of unique sequences remains stable in overtime in both the blood (B) and semen (D). An unpaired $t$ test was used to generate the indicated $p$ values. 
bioRxiv preprint doi: https://doi.org/10.1101/2020.01.28.924225; this version posted January 29, 2020. The copyright holder for this preprint (which was not certified by peer review) is the author/funder. All rights reserved. No reuse allowed without permission.

S031 Full-Length Env

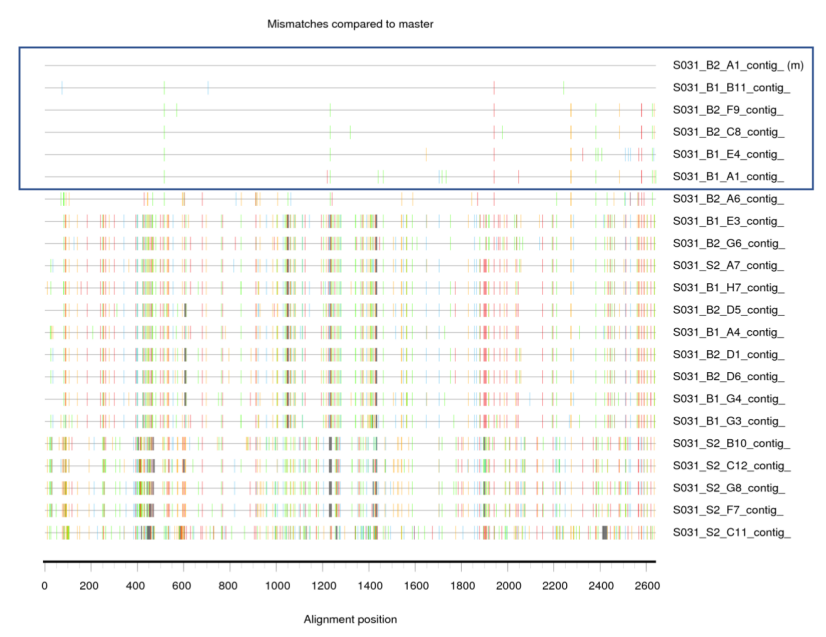

S031 Env V1/V3

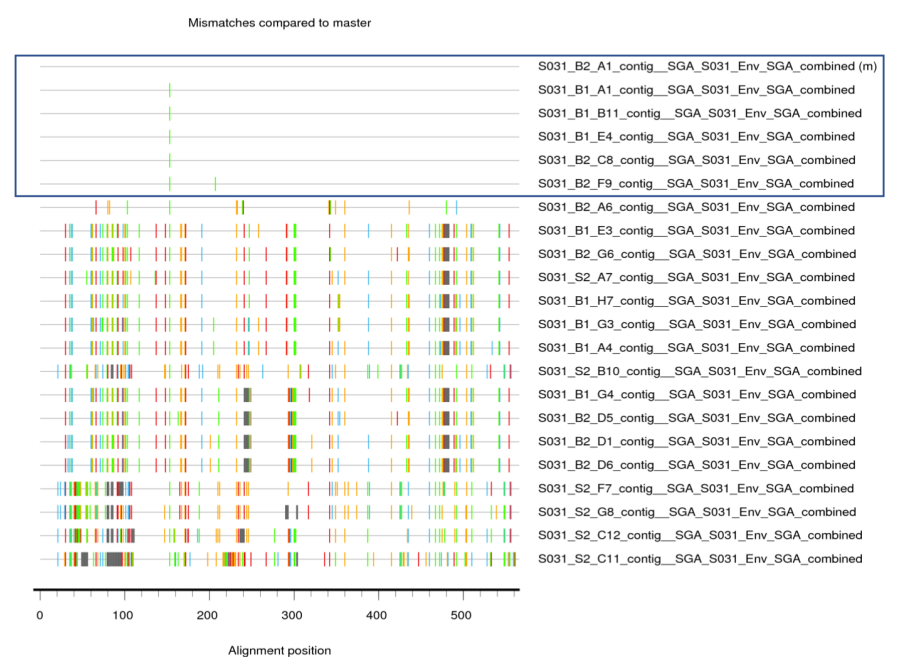

Figure 4. Highlighter plot of paired full-length $e n v$ and $e n v \mathrm{V1} / \mathrm{V3}$ sequences. SGA-derived full-length envelope sequences and the corresponding V1/V3 region only are shown on the left and right, respectively. Boxed sequences represent those that are identical in the V1/V3 amplicon, and nearly identical over the full envelope amplicon. 
A. S031

Before STI Treatment

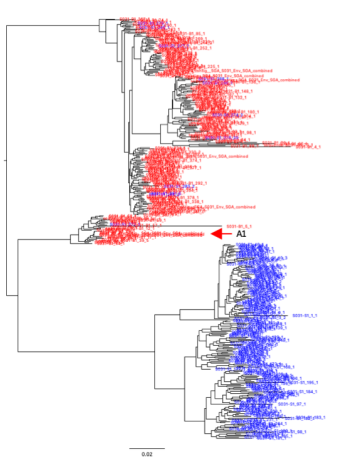

S031 relative infectivity

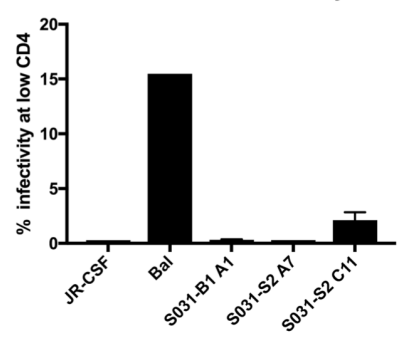

B.
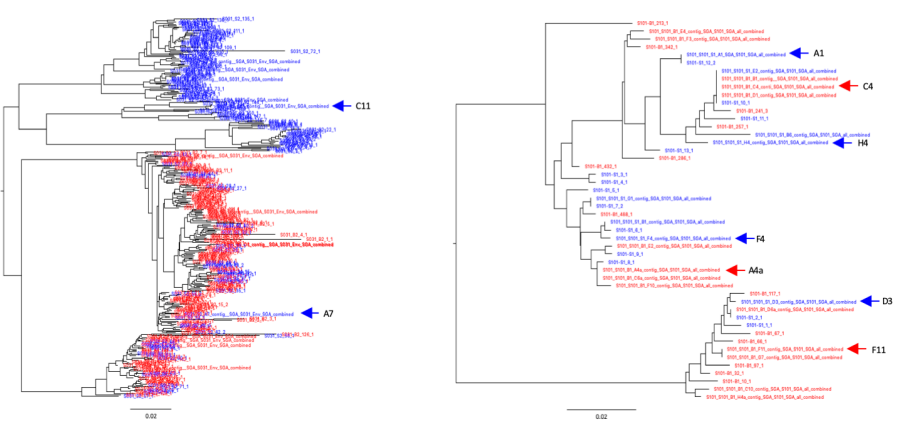

S101 relative infectivity

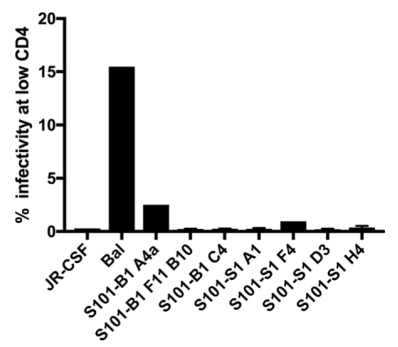

C. C061

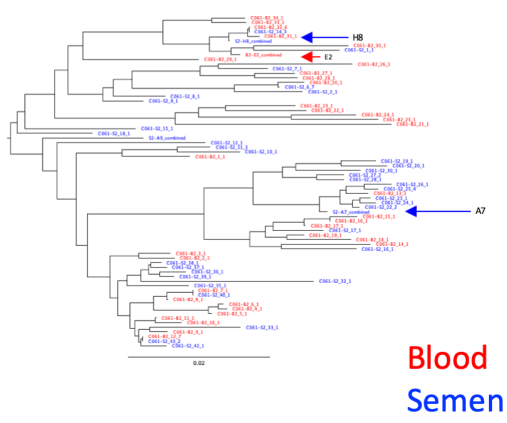

C061 relative infectivity

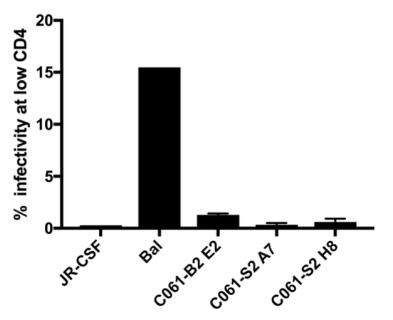

Figure 5. SGA-derived HIV-1 envelopes from the semen are T-cell tropic. (A-C) Neighbor-joining trees of env V1/V3 blood (red) and semen (blue) derived sequences. The graphs below depicts the ability of SGAderived envelopes from blood and semen to enter cells expressing low densities of CD4. Colored arrows on the trees depict the locations of the envelopes used in the graphs below. JR-CSF and Bal are T-tropic and M-tropic controls, respectively. Data represent the average of three biological replicates. 
A.

Semen
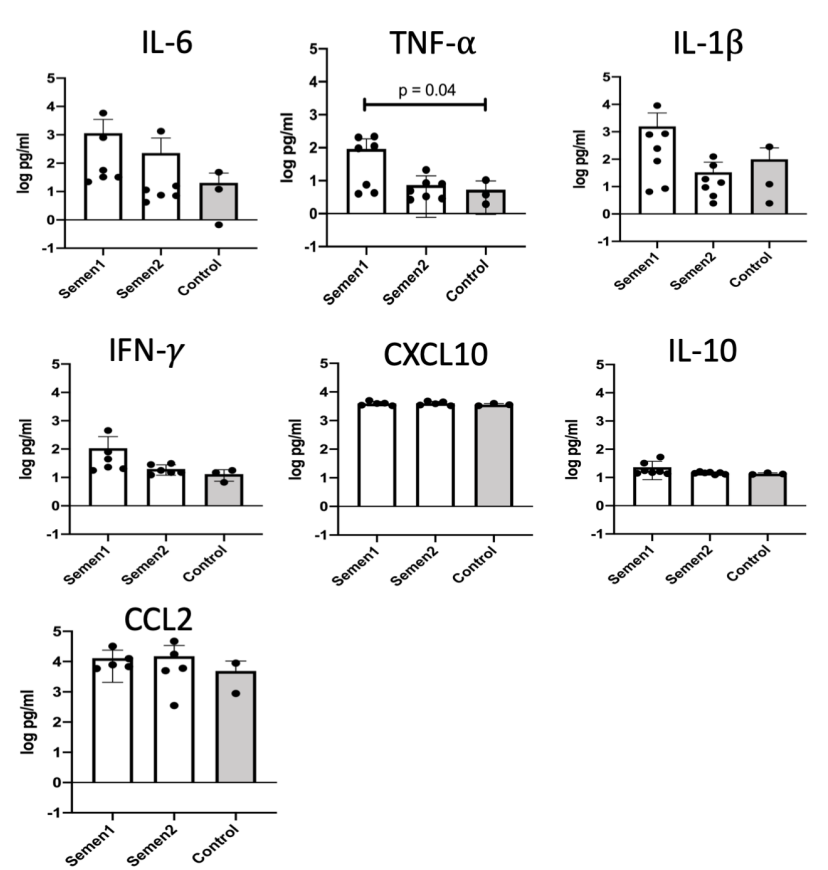

B.

Blood
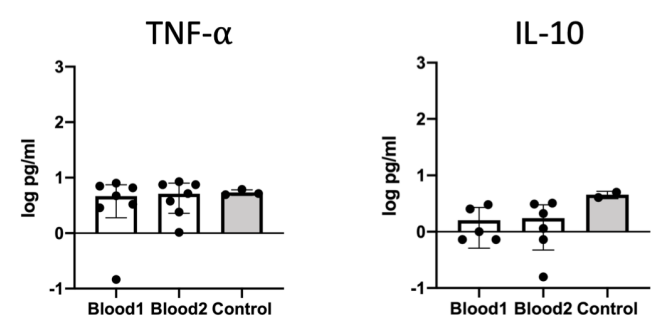

$\mathrm{CCL} 2$

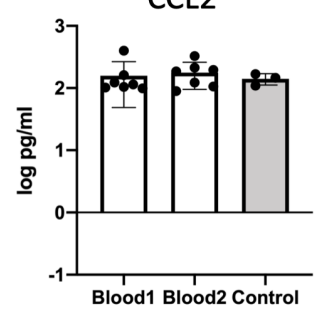

CXCL10

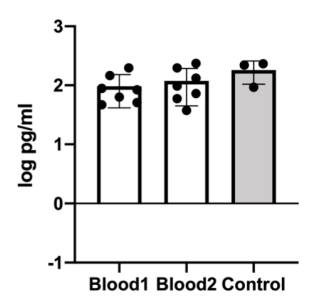

Figure 6. Cytokine/chemokine analysis in semen and blood before and after antibiotic treatment of the STI. Cytokine/chemokine concentrations in semen (A) and blood (B) were measured before and after STI treatment. The values were compared to a group of HIV+ men without a concurrent STI (labeled as "control", and depicted by the grey bars). A one-way ANOVA was used to generate the indicated p value. 
A. Pre-STI Treatment

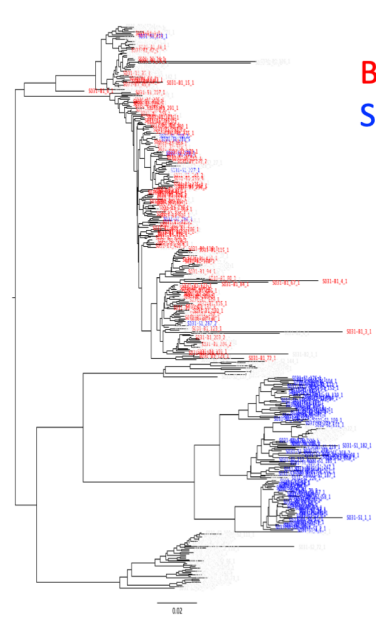

Semen sequences that cluster independently of blood:
Post-STI Treatment

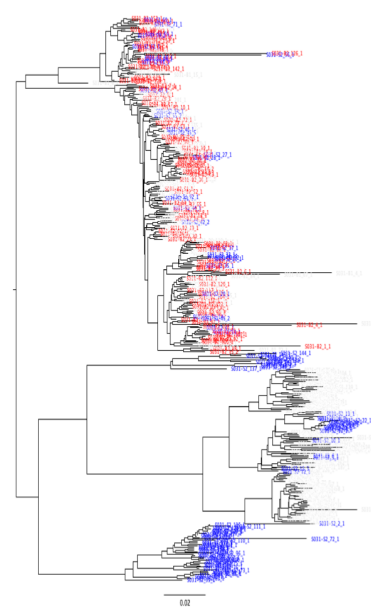

$107 / 152(70.4 \%)$
B.

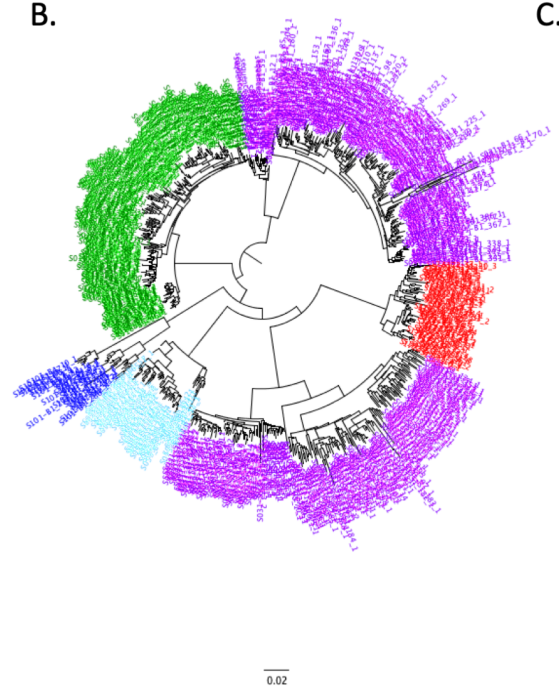

C.

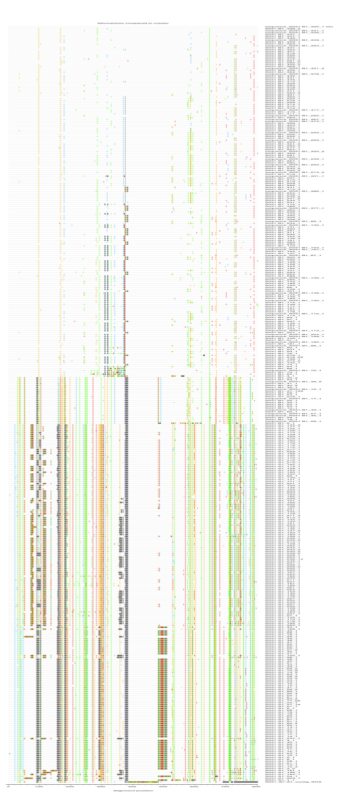

Figure 7. Characterization of a super-infection. A) Pre and post-STI treatment neighbor-joining phylogenetic trees depicting a distinct semen-only lineage from participant S031. Semen-derived sequences are shown in blue, blood-derived sequences are shown in red. The percent of all semen-derived sequences that cluster independently from the blood is shown at the bottom. B) A neighbor-joining phylogenetic tree containing blood and semen-derived sequences from five participants. Sequences from each participant are shown in a different color, sequences from S031 are purple. C) Highlighter plot depicting recombination between blood and semenderived sequences from S031. 